\title{
Punikalaginin Kolistin Dirençli Acinetobacter baumannii Suşlarına Karşı Tek Başına ve Kolistin ile Kombinasyon Halinde Antimikrobiyal Aktivitesinin Değerlendirilmesi
}

\author{
Elif Odabaş Köse* \\ Akdeniz Üniversitesi, Sağlık Hizmetleri Meslek Yüksekokulu, Antalya, Türkiye, (ORCHID: 0000-0002-3943-571X), elifkose@akdeniz.edu.tr, elifkose@gmail.com
}

(International Conference on Design, Research and Development (RDCONF) 2021 - 15-18 December 2021)

(DOI: 10.31590/ejosat.1041147)

\begin{abstract}
ATIF/REFERENCE: Odabaş Köse E (2021). Punikalaginin Kolistin Dirençli Acinetobacter baumannii Suşlarına Karşı Tek Başına ve Kolistin ile Kombinasyon Halinde Antimikrobiyal Aktivitesinin Değerlendirilmesi. Avrupa Bilim ve Teknoloji Dergisi, (32), 670-674.

$\ddot{\mathbf{O} z}$

Bu çalışmanın amacı, punikalaginin tek başına ve kolistin ile kombinasyon halinde antimikrobiyal aktivitesini kolistine dirençli $A$. baumannii suşları üzerinde değerlendirmektir. Çalışmada test edilmek üzere beş adet kolistine dirençli A. baumannii suşu kullanılmıştır. Suşlara karşı punikalagin ve kolistinin antimikrobiyal aktivitelerini saptamak için sıvı mikrodilüsyon testi yapılarak Minimum İnhibisyon Konsantrasyonları (MİK) belirlenmiştir. Bu iki ajanın kombinasyon aktiviteleri ise Dama Tahtası (Checkerboard) Sinerji Testi ile değerlendirilmiştir. Sıvı mikrodilüsyon testinin sonuçlarına göre tüm suşlara karşı punikalaginin MİK değeri $256 \mu$ g/ml, kolistinin MİK değerleri ise iki suşta $32 \mu \mathrm{g} / \mathrm{ml}$, diğer üç suşta $8 \mu \mathrm{g} / \mathrm{ml}$ olarak tespit edilmiştir. Checkerboard sinerji testi ile kombinasyon etkileşimlerinin belirlenmesinde Fraksiyonel İnhibitör Konsantrasyon İndeksi (FİKİ) hesaplanmıştır. Buna göre kolistin ve punikalagin kombinasyonunun FİKİ değerleri iki suş için 1.12, diğer üç suş için ise 1.03 olarak bulunmuştur. Sonuç olarak, punikalagin kolistin dirençli $A$. baumannii suşları üzerinde antimikrobiyal aktivite göstermiştir. Kolistin ile kombinasyonunun ise tüm test edilen suşlar üzerinde indiferan etkili olduğu tespit edilmiştir. Hiçbir suş üzerinde sinerjistik etki gözlenmemiştir. Bunun yanısıra herhangi bir antagonistik etki de saptanmamıştır.
\end{abstract}

Anahtar Kelimeler: Acinetobacter baumannii, kolistin, punikalagin, indiferan etki

\section{Evaluation of the Antimicrobial Activity of Punicalagin Alone and in Combination with Colistin Against Colistin-Resistant Acinetobacter baumannii Strains}

\begin{abstract}
The aim of this study was to evaluate the antimicrobial activity of punicalagin alone and in combination with colistin on colistin-resistant A. baumannii strains. Five colistin-resistant A. baumannii strains were used to be tested in the study. Broth microdilution test was performed to evaluate the antimicrobial activities of punicalagin and colistin against strains and Minimum Inhibition Concentrations (MIC) were determined. Combination activities of these two agents were evaluated with the Checkerboard Synergy Test. According to the results of the broth microdilution test, the MIC value of punicalagin against all strains was $256 \mu \mathrm{g} / \mathrm{ml}$, the MIC values of colistin were found to be $32 \mu \mathrm{g} / \mathrm{ml}$ on two strains and $8 \mu \mathrm{g} / \mathrm{ml}$ on the other three strains. The Fractional Inhibitory Concentration Index (FICI) was calculated to determine combination interactions with the Checkerboard synergy test. Accordingly, the FICI values of the combination of colistin and punicalagin were found as 1.12 for two strains, 1.03 for the other three strains. In conclusion, punicalagin showed antimicrobial activity on colistin-resistant $A$. baumannii strains. It was determined that the combination with colistin had an indifferent effect on all tested strains. No synergistic effects were observed on any of the strains. In addition, no antagonistic effects were detected.
\end{abstract}

Keywords: Acinetobacter baumannii, colistin, punicalagin, indifferent effect

Sorumlu Yazar: elifkose@akdeniz.edu.tr, elifkose@gmail.com 


\section{Giriş}

Acinetobacter baumannii (A. baumannii) Gram negatif, aerobik, hareketsiz ve non-fermentatif bir bakteridir (Howard ve ark., 2012). A. baumannii, hastane infeksiyonlarında en sik karşılaşılan bakterilerden biri olup, üriner sistem enfeksiyonları, bakteriyemi, pnömoni ve yara infeksiyonları gibi ciddi infeksiyonlara neden olmaktadır (Li ve ark., 2020). Antibiyotiklere karşı yüksek oranda direnç geliştirme yeteneğine sahip olan bu bakteri tedavisinde kullanılan birçok antibiyotiğe karşı dirençlidir. Acinetobacter infeksiyonları 1970'lerin başına kadar geniş spektrumlu $\beta$-laktamlar, sefalosporinler ve tetrasiklinler gibi çoğu geleneksel antibiyotik ile tedavi edilebilirken, kolistin dahil olmak üzere birçok antimikrobiyal ajan bu bakterilere karşı artık etkinliğini kaybetmiştir (Asif ve ark., 2018). Kolistin, ilaca dirençli Gram-negatif bakterilerin neden olduğu enfeksiyonların tedavisinde hem monoterapide hem de kombinasyon tedavisinde yaygin olarak kullanılan bir polimiksin antibiyotik ajanıdır. Ne yazık ki tüm dünyada kolistine dirençli A. baumannii suşları her geçen yıl bildirilmektedir. (Rodjun ve ark., 2020). Bu yüzden, A. baumannii Amerika Enfeksiyon Hastalıkları Derneği tarafından insan sağlığını ciddi şekilde tehdit eden ve tedavisinde yeni antibiyotiklere acilen ihtiyaç duyulan altı dirençli patojenden biri olarak tanımlanmıştır (Qureshi ve ark., 2015; Ayoub Moubareck ve Hammoudi Halat, 2020).

Günümüzde dirençli bakterilerin neden olduğu infeksiyonların üstesinden gelmek için antibiyotiklere alternatif olabilecek yeni antimikrobiyal ilaçların geliştirilmesi amaçlı birçok çalışma yapılmaktadır. Geçmişten günümüze bitkiler pek çok ülkede, birçok hastalığın tedavisinde kullanılmaktadır. Nar (Punica granatum L.) Punicaceae ailesinden çalı veya küçük ağaç formunda olan çok yıllık bir bitkidir (Trabelsi ve ark., 2020). Doğal olarak İran'a özgü olan nar, oradan Türkiye dahil Asya, Kuzey Afrika ve Güney Avrupa'ya yayılmıştır. (Duman ve ark., 2009). Yenilebilir en eski meyvelerden biri olan narın meyveleri, kabukları ve kökleri birçok ülkede yerel şifacılar tarafından bitkisel ilaçlarda yaygın olarak kullanılmaktadır (Al-Zoreky, 2009). Narın, Ayurvedik ve Unani sistemlerinde inflamatuar hastalıkları ve sindirim sistemi bozukluklarını tedavi etmek için kullanıldığına dair kayıtlar bulunmaktadır. Eski Mısırlılar narı tenyaların ve diğer parazitlerin tedavisinde kullanmışlardır (Celiksoy ve Heard, 2021). Narın meyveleri asidoz, dizanteri, mikrobiyal enfeksiyonlar, ishal, helmintiyazis, kanama ve solunum yolu patolojilerini tedavi etmek için kullanılmıştır. (Duman ve ark., 2009). Daha yakın zamanlarda, nar, cilt enfeksiyonları, diş hekimliği, gıda koruma vb. gibi çeşitli alanlarda antimikrobiyal potansiyeli nedeniyle kapsamlı ve bilimsel olarak incelenmiştir (Celiksoy ve Heard, 2021).

Nar kabuğu, punikalagin, punikalin, gallagik asit, ellagik asit ve ellagik asit glikozitleri gibi ellagitaninler açısından zengindir. Punikalagin (2,3-heksahidroksi-difenoil-4,6gallagilglikoz) yüksek moleküler ağırlıklı, suda çözünür en önemli ellagitanin bileşiklerinden birisidir (Aqil ve ark., 2012). Nar kabuğundaki doğal biyoaktif bileşik olarak nitelendirilen punikalaginin antioksidan (Seeram ve ark., 2005; Aqil ve ark., 2012), antimikrobiyal (Xu ve ark., 2017; Gosset-Erard ve ark., 2021), antikanser (Ganesan ve ark., 2020; Berdowska ve ark., 2021), antiviral (Houston ve ark., 2017; Du ve ark., 2021) aktivite gibi birçok özelliğe sahip olduğu bildirilmektedir.
Bu bilgilerden yola çıkarak bu çalışmanın amacı kolistin dirençli A. baumannii suşlarına karşı punikalaginin tek başına antimikrobiyal ve kolistin ile kombinasyon aktivitesinin değerlendirilmesidir. Literatür bilgilerine göre dirençli $A$. baumannii suşlarına karşı punikalaginin kombinasyon etkisi daha önce araştırılmamıştır. Böylelikle bu çalışma ile elde edilen sonuçların punikalagin ile yapılacak ileriki araştırmalar için yol gösterici olacağ düşünülmektedir.

\section{Materyal ve Metot}

\subsection{Bakteri Suşları ve Antimikrobiyal Ajanlar}

Akdeniz Üniversitesi Hastanesi Merkez Laboratuvarı Mikrobiyoloji bölümünde klinik örneklerden izole edilmiş kolistine dirençli A. baumannii suşları arasından rastgele seçilen beş adet suş çalışmaya alınmıştır. Suşlar çalışma öncesinde derin dondurucudan çıkarılarak Kanlı agar besiyerine (Becton Dickinson, Franklin Lakes, NJ, USA) art arda iki kez pasajlanıp, normal atmosferde, $35 \pm 2^{\circ} \mathrm{C}$ 'de bir gece inkübe edilmiştir. Üreyen kolonilerden daha sonra taze kültür pasajları yapılarak saf olarak elde edilen bakteri kolonileri testlerde kullanılmıştır.

Kolistin antibiyotiğinin stok çözeltisi için, Kolistin Sülfat (C4461, Sigma-Aldrich, St. Louis, MO, USA)) kullanılmış, distile suda çözülerek stok çözeltisi porsiyonlanarak $-80^{\circ} \mathrm{C}$ 'de saklanmıştır. Punikalagin (C6201-P063, TransMIT, Giessen, Germany) besiyerinde çözülerek stok solüsyon testin uygulanacağı zaman günlük olarak hazırlanmıştır.

\subsection{Sıvı Mikrodilüsyon Yöntemi}

Punikalagin ve kolistinin antimikrobiyal aktivitelerini saptamak için CLSI (Clinical Laboratory Standarts Institute) tarafindan önerilen sıvı mikrodilüsyon testi yapılarak Minimum İnhibisyon Konsantrasyonları (MİK) belirlenmiştir (CLSI, 2018). Test 96 kuyucuklu steril mikrodilüsyon plaklarında yapılmış olup besiyeri olarak katyon ayarlı Mueller Hinton Broth (MHB, Merck KGaA, Darmstadt, Germany) kullanılmıştır. İlk olarak, her bir kuyucuğa $50 \mu \mathrm{l}$ besiyeri eklenmiştir. Test edilecek antimikrobiyallerin başlangıç konsantrasyonları hazırlanarak (kolistin için $512 \mu \mathrm{g} / \mathrm{ml}$, punikalagin için $1024 \mu \mathrm{g} / \mathrm{ml}$ ) ilk kuyucuklara $50 \mu \mathrm{l}$ konulup seri dilüsyonları yapılmıştır. Tüm bakterilerin steril \%0.9 NaCl solüsyonunda $0.5 \mathrm{McF}$ Farland $\left(1 \times 10^{8}\right.$ hücre/ml) standart yoğunluğuna göre süspansiyonları hazırlanmıştır. Bakteri süspansiyonundan $50 \mu$ l alınarak tüm kuyucuklara eklenmiştir. Her bir bakteri için bakteri üreme kontrolü (MHB+bakteri) ve her mikrodilüsyon plağı için besiyeri sterilite kontrolü (MHB) çalışılmıştır. Ayrıca Escherichia coli NCTC 13846 suşu kolistin dirençliliğini doğrulamak için kalite kontrol suşu olarak kullanılmıştır. Mikrodilüsyon plakları $35 \pm 2^{\circ} \mathrm{C}$ 'de $16-20$ saat süre ile aerop koşullarda etüvde inkübe edilmiştir. Antibiyotik içeren kuyucuklardaki üreme yoğunluğu her test setinde kullanılan kontrol kuyucuklarındaki (antibiyotiksiz) üreme yoğunluğu ile kıyaslanarak MIKK değerleri belirlenmiştir. MİK, bakterilerin mikrodilüsyon kuyucuklarındaki üremesini tamamen inhibe eden ve çıplak gözle belirlenebilen en düşük antimikrobik ilaç konsantrasyonudur. Her bir deney üç kere tekrar edilmiştir. 


\subsection{Dama Tahtası (Checkerboard) Sinerji Testi}

Bakteri suşları üzerinde punikalagin ile kolistinin kombinasyonunun etkisini test etmek için dama tahtası (checkerboard) yöntemi uygulanmıştır (Moody, 2007). Bu test, mikrodilüsyon esasına dayanan sinerji testlerinden biridir. Her iki antimikrobiyal ajanın kombinasyon aktivitesi, her bir bakteri suşu için 96 kuyucuklu plak üzerinde test edilmiştir ve besiyeri olarak katyon ayarlı MHB kullanılmıştır. MIKK değerlerinin dört kat üstü dilüsyon (4xMİK) ve beş kat altı dilüsyon (1/32xMİK) kullanılarak iki farklı ajan kombinasyonunun etkinliği test edilmiştir. İlk olarak katyon ayarlı MHB içeren tüplerde her bir ajanın belirlenen konsantrasyonlarından geometrik dilüsyonları hazırlanmıştır. Kolistinin hazırlanan çözeltileri plak dikey düzleminde yukarıdan aşağıya doğru konulurken, punikalaginin çözeltileri ise yatay düzlemde sağdan sola doğru konulmuştur.
Böylelikle her bir kuyucukta iki ajanın farklı konsantrasyondaki çözeltilerini içeren kombinasyonları elde edilmiştir. Buna göre tüplerde geometrik dilüsyonları hazırlanan her bir ajandan $50 \mu \mathrm{l}$, toplamda bir kuyucukta $100 \mu$ l madde konsantrasyonu elde edilmiştir. Bakteri inokulumu $0.5 \mathrm{McFarland}\left(1 \times 10^{8}\right.$ hücre $\left./ \mathrm{ml}\right)$ standart yoğunluğuna göre steril $\% 0.9 \mathrm{NaCl}$ solüsyonunda hazırlanmıştır ve kuyucuklardaki en son bakteri konsantrasyonu $5 \times 10^{5}$ hücre/ml olacak şekilde her bir kuyucuğa $10 \mu$ l eklenmiştir. Plak üzerinde antimikrobiyal ajan içermeyen üreme kontrol kuyucuğu ve bakteri içermeyen sterilite kontrol kuyucuğu da hazırlanmıştır. Ayrıca her iki ilacın MİK değerleri aynı plak üzerinde dama tahtası testi ile eş zamanlı olarak tekrar çalışılmıştır. Mikrodilüsyon plakları $35 \pm 2^{\circ} \mathrm{C}^{\prime} \mathrm{de} 16-20$ saat süre ile aerop koşullarda etüvde inkübe edilmiştir. Her bir deney üç kere tekrar edilmiştir. Dama tahtası testi uygulaması sonucu elde edilen 96 kuyucuklu plağının temsili görünümü Şekil 1'de verilmiştir.

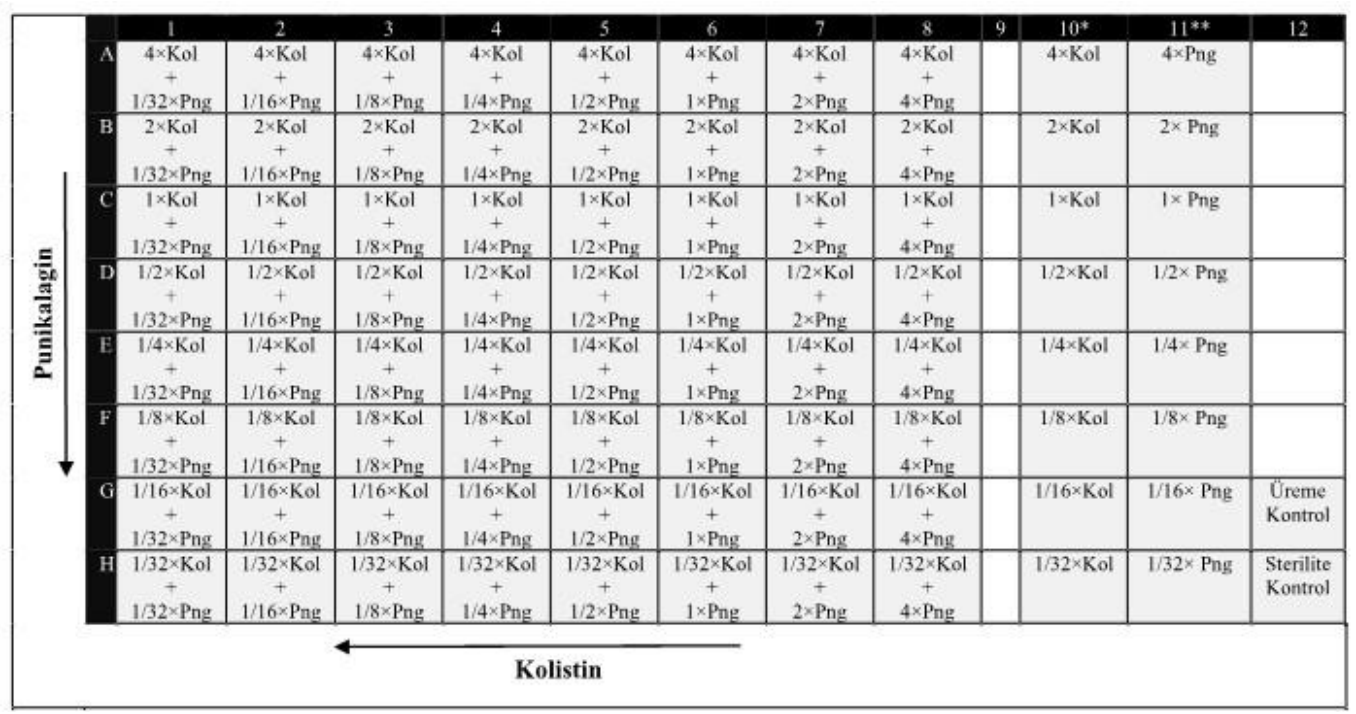

Şekil 1. Dama tahtası sinerji testinin temsili uygulanma şekli. Kol: Kolistin, Png: Punikalagin,

*: Eş zamanlı çalışılan kolistin MIKK, **: Eş zamanlı çalışılan punikalagin MIKK

Sonuçların yorumlanması için önce her iki antibiyotiğin ayr1 ayr1 Fraksiyonel İnhibisyon Konsantrasyonu (FIK) hesaplanmıştır. Sonra da FİK indeks (FİKİ) bulunmuştur.

$\mathrm{FİK}_{\mathrm{a}}=\mathrm{a}$ maddesinin kombinasyondaki MİK değeri/a maddesinin tek başına MİK değeri

$\mathrm{FI}_{\mathrm{b}}=\mathrm{b}$ maddesinin kombinasyondaki MİK değeri/b maddesinin tek başına MİK değeri

$F \dot{F I} \dot{I}=F^{\prime I K}{ }_{a}+F^{\prime} K_{b}$

Buna göre çıkan değer; Fİ $\dot{I} \leq 0.5$ ise sinerjistik etki, $0.5<$ FIKI $\leq 4$ ise indiferan etki, Fİİ $>4$ ise antagonistik etki olarak yorumlanmıştır.

\section{Araştırma Sonuçları ve Tartışma}

\subsection{Minimum İnhibitör Konsantrasyon (MIKK) Değerlerinin Belirlenmesi}

Punikalagin ve kolistinin A. baumannii suşları üzerine antimikrobiyal etkilerinin belirlenmesi için sıvı mikrodilüsyon testi uygulanarak MIK değerleri saptanmıştır. Buna göre e-ISSN: 2148-2683 punikalagin tüm suşlara karşı $256 \mu \mathrm{g} / \mathrm{ml}$ MİK değeri ile antimikrobiyal aktivite göstermiştir. Kolistinin MİK değerleri ise iki suşta $32 \mu \mathrm{g} / \mathrm{ml}$, diğer üç suşta $8 \mu \mathrm{g} / \mathrm{ml}$ olarak tespit edilmiştir. E. coli NCTC 13846 için kolistin MIK değeri $4 \mu \mathrm{g} / \mathrm{ml}$ olarak saptanmıştır. CLSI tarafindan kolistin için belirlenen MIK değerlerine göre $\leq 1 \mu \mathrm{g} / \mathrm{ml}$ duyarlı, $\geq 4 \mu \mathrm{g} / \mathrm{ml}$ dirençli olarak kabul edilmektedir. $\mathrm{Bu}$ kriterlere göre beş A. baumannii suşunun da kolistine dirençli olduğu doğrulanmıştır. Uygulanan mikrodilüsyon testi sonuçlarına göre $A$. baumannii suşları üzerinde elde edilen MİK değerleri Tablo 1'de verilmiştir.

Literatürde punikalaginin $A$. baumannii üzerine etkisinin araştırıldığ 1 bir adet çalışma bulunmuştur. Bu çalışmada bizim bulgularımızdan farklı olarak A. baumannii'ye karşı punikalaginin herhangi bir antimikrobiyal aktivite göstermediğini saptamışlardır (Álvarez-Martínez ve ark., 2021). Punikalaginin nar ekstresi içinde antimikrobiyal özelliğe sahip asıl bileşik olduğunu ve birçok mikroorganizma türüne karşı antimikrobiyal etki gösterdiğini ortaya koyan birçok araştırma mevcuttur. Xu ve ark. (2017), $0.25 \mathrm{mg} / \mathrm{ml}$ MÍK değeri ile punikalaginin Staphylococcus aureus'a karşı iyi aktivite gösterdiğini ortaya koymuşlardır. Gosset-Erard ve ark. (2021) yaptıkları çalışmalarında, punikalagini nar kabuğu ekstrelerindeki antibakteriyel özellikteki bileşik olarak tanımlamışlardır. Punikalaginin hem $\alpha$ hem de $\beta$ anomerik formlarının, çeşitli gram 
pozitif ve gram negatif bakteriler ile bir maya türü olan Candida albicans'a karşı 0.3-1.2 $\mu \mathrm{g} / \mathrm{ml}$ aralığındaki MİK değerleri ile aktivite gösterdiğini bulmuşlardır. Metisilin dirençli $S$. aureus (MRSA) suşlarına karşı punikalaginin etkisinin araştırıldığ 1 bir diğer çalışmada ise $20 \mathrm{~mm}$ inhibisyon zonu ve $61.5 \mu \mathrm{g} / \mathrm{ml}$ MİK değeri ile test edilen tüm suşlara karşı punikalaginin antibakteriyel aktivite gösterdiği saptanmıştır (Machado ve ark., 2002). Li ve ark. (2014), 10 Salmonella suşuna karş1 punikalaginin 250-1000 $\mu \mathrm{g} / \mathrm{ml}$ aralığında MiK değerleri ile antimikrobiyal etki gösterdiğini bulmuşlardır.

\subsection{Dama Tahtası (Checkerboard) Sinerji Testinin sonuçları}

Beş A. baumannii suşu üzerine punikalagin ile kolistin kombinasyonunun etkisi dama tahtası (checkerboard) sinerji testi ile değerlendirilmiştir. Test sonucunda punikalagin ve kolistin kombinasyonu için hesaplanan FİKİ değerlerine göre iki suş için 1.12, diğer üç suş için ise 1.03 FİKİ değerleri elde edilmiştir. Bu sonuçlar yorumlandığında tüm suşlar üzerinde iki ajanın kombinasyonunun indiferan etkili olduğu tespit edilmiştir. Hiçbir suşa karş1 kombinasyon sinerjistik etkileşim gösterememiştir. Bunun yanısıra herhangi bir antagonistik etki de saptanmamıştır. Sinerji testinin sonuçları Tablo 1'de verilmiştir.

Tablo 1. Tüm suşlara karşı punikalagin ve kolistinin antimikrobiyal ve kombinasyon aktivitelerinin sonuçları

\begin{tabular}{|c|c|c|c|c|c|c|c|c|}
\hline \multirow[b]{2}{*}{ Bakteri suşları } & \multicolumn{3}{|c|}{ Png } & \multicolumn{3}{|c|}{ Kol } & \multicolumn{2}{|c|}{ Png+Kol } \\
\hline & $\mathbf{M I ̇ K}_{\mathbf{T}}$ & MÍKK & FİKPng & $\mathbf{M I ̇ K}_{T}$ & MİKK $_{K}$ & FİKKol & FÍKI & Sonuç \\
\hline A. baumannii 1 & 256 & 256 & 1 & 8 & 0.25 & 0.03 & 1.03 & İndiferan \\
\hline A. baumannii 2 & 256 & 256 & 1 & 8 & 0.25 & 0.03 & 1.03 & İndiferan \\
\hline A. baumannii 3 & 256 & 256 & 1 & 32 & 4 & 0.12 & 1.12 & İndiferan \\
\hline A. baumannii 4 & 256 & 256 & 1 & 32 & 4 & 0.12 & 1.12 & İndiferan \\
\hline A. baumannii 5 & 256 & 256 & 1 & 8 & 0.25 & 0.03 & 1.03 & İndiferan \\
\hline
\end{tabular}

Png: Punikalagin, Kol: Kolistin, Mi்K : Tek başına MİK ( $\mu \mathrm{g} / \mathrm{ml})$, MİKK$_{\mathrm{K}}$ Kombinasyonda iken MİK $(\mu \mathrm{g} / \mathrm{ml})$

Literatürde punikalaginin A. baumannii’ye karş1 kombinasyon aktivitesinin araştırıldığı bir çalışmaya rastlanmamıştır. Farklı mikroorganizmalar üzerinde kombinasyon aktivite araştırmaları da sınırlıdır. Mun ve ark. (2018), MRSA üzerine punikalagin ve oksasilin kombinasyonunun etkisini araştırdıkları çalışmalarında test ettikleri tüm suşlar üzerinde sinerjistik etki tespit etmişlerdir. da Silva ve ark. (2020) punikalagin ile nistatin kombinasyonunun iki Candida suşu üzerinde antifungal etkinliği arttırdığını tespit etmişlerdir. Candida türleri ile ilgili yapılan diğer bir çalışmada, punikalagin ve flukonazolün $C$. albicans ve $C$. parapsilosis üzerinde sinerjistik etki gösterdiği saptanmıştır (Endo ve ark., 2010).

\section{Sonuç}

Sonuç olarak, bu çalışmada kolistin dirençli $A$. baumannii suşları üzerine punikalaginin antimikrobiyal ve kolistin ile kombinasyon aktivitesi değerlendirilmiştir. Elde edilen sonuçlara göre punikalagin A. baumannii suşları üzerinde antimikrobiyal aktivite göstermiştir. Dirençli suşlar üzerinde punikalaginin tek başına gösterdiği bu etkinin değerli olduğu düşünülmektedir.

Punikalaginin kolistin ile kombinasyon aktivitesinin değerlendirilmesi sonucunda test edilen suşlar üzerine kombinasyonun indiferan etkili olduğu tespit edilmiştir. Tedavi amaçlı kullanılan iki antimikrobiyal ajanın sinerjistik etkili olması tedavide başarıyı arttıran bir etkileşimdir. Kombinasyon tedavileri günümüzde dirençli bakterilerin tedavisinde çoğunlukla uygulanmaktadır. Dirençli bakterilere çözüm arayışları içinde doğal bileşikler ile antibiyotiklerin kombin edilerek aktivitelerinin arttırılmasına dayalı araştırmalar yapılmaktadır. Bu çalışmalarda antibiyotikler ile sinerjistik etkileşimli bir doğal bileşik alternatif bir ajan olarak görülmektedir. Bu çalışmada ise punikalagin ile kolistin kombinasyonu beklenen sinerjistik etkileşimi gösterememiştir. Bununla birlikte punikalaginin bu suşlar üzerinde bir antimikrobiyal aktiviteye sahip olduğu gözönünde bulundurulduğunda dirençli $A$. baumanni infeksiyonlarını tedavi etmek için kullanılan farklı gruptaki antibiyotikler ile kombine edilerek araştırılması önerilmektedir.

\section{Kaynakça}

Álvarez-Martínez, F. J., Rodríguez, J. C., Borrás-Rocher, F., Barrajón-Catalán, E., \& Micol, V. (2021). The antimicrobial capacity of Cistus salviifolius and Punica granatum plant extracts against clinical pathogens is related to their polyphenolic composition. Scientific reports, 11(1), 1-12.

Al-Zoreky, N. S. (2009). Antimicrobial activity of pomegranate (Punica granatum L.) fruit peels. International journal of food microbiology, 134(3), 244-248.

Aqil, F., Munagala, R., Vadhanam, M. V., Kausar, H., Jeyabalan, J., Schultz, D. J., \& Gupta, R. C. (2012). Anti-proliferative activity and protection against oxidative DNA damage by punicalagin isolated from pomegranate husk. Food Research International, 49(1), 345-353.

Asif, M., Alvi, I. A., \& Rehman, S. U. (2018). Insight into Acinetobacter baumannii: pathogenesis, global resistance, mechanisms of resistance, treatment options, and alternative modalities. Infection and drug resistance, 11, 1249.

Ayoub Moubareck, C., \& Hammoudi Halat, D. (2020). Insights into Acinetobacter baumannii: a review of microbiological, virulence, and resistance traits in a threatening nosocomial pathogen. Antibiotics, 9(3), 119.

Berdowska, I., Matusiewicz, M., \& Fecka, I. (2021). Punicalagin in Cancer Prevention-Via Signaling Pathways Targeting. Nutrients, 13(8), 2733.

Celiksoy, V., \& Heard, C. M. (2021). Antimicrobial Potential of Pomegranate Extracts. In Pomegranate. IntechOpen.

Clinical and Laboratory Standards Institute (CLSI). 2018. Performance Standards for Antimicrobial Susceptibility 


\section{Avrupa Bilim ve Teknoloji Dergisi}

Testing. 28th ed. CLSI Supplement M100. Wayne, PA: Clinical and Laboratory Standards Institute.

da Silva, R. A., Ishikiriama, B. L. C., Ribeiro Lopes, M. M., de Castro, R. D., Garcia, C. R., Porto, V. C., ... \& Lara, V. S. (2020). Antifungal activity of Punicalagin-nystatin combinations against Candida albicans. Oral Diseases, 26(8), 1810-1819.

Du, R., Cooper, L., Chen, Z., Lee, H., Rong, L., \& Cui, Q. (2021). Discovery of chebulagic acid and punicalagin as novel allosteric inhibitors of SARS-CoV-2 3CLpro. Antiviral research, 190, 105075.

Duman, A. D., Ozgen, M., Dayisoylu, K. S., Erbil, N., \& Durgac, C. (2009). Antimicrobial activity of six pomegranate (Punica granatum L.) varieties and their relation to some of their pomological and phytonutrient characteristics. Molecules, 14(5), 1808-1817.

Endo, E. H., Cortez, D. A. G., Ueda-Nakamura, T., Nakamura, C. V., \& Dias Filho, B. P. (2010). Potent antifungal activity of extracts and pure compound isolated from pomegranate peels and synergism with fluconazole against Candida albicans. Research in Microbiology, 161(7), 534-540.

Ganesan, T., Sinniah, A., Chik, Z., \& Alshawsh, M. A. (2020). Punicalagin regulates apoptosis-autophagy switch via modulation of annexin A1 in colorectal cancer. Nutrients, 12(8), 2430.

Gosset-Erard, C., Zhao, M., Lordel-Madeleine, S., \& Ennahar, S. (2021). Identification of punicalagin as the bioactive compound behind the antimicrobial activity of pomegranate (Punica granatum L.) peels. Food Chemistry, 352, 129396.

Houston, D. M., Bugert, J. J., Denyer, S. P., \& Heard, C. M. (2017). Potentiated virucidal activity of pomegranate rind extract (PRE) and punicalagin against Herpes simplex virus (HSV) when co-administered with zinc (II) ions, and antiviral activity of PRE against HSV and aciclovir-resistant HSV. PloS one, 12(6), e0179291.

Howard, A., O’Donoghue, M., Feeney, A., \& Sleator, R. D. (2012). Acinetobacter baumannii: an emerging opportunistic pathogen. Virulence, 3(3), 243-250.

Li, G., Yan, C., Xu, Y., Feng, Y., Wu, Q., Lv, X., ... \& Xia, X. (2014). Punicalagin inhibits Salmonella virulence factors and has anti-quorum-sensing potential. Applied and environmental microbiology, 80(19), 6204-6211.
Li, J., Fu, Y., Zhang, J., Zhao, Y., Fan, X., Yu, L., ... \& Li, C. (2020). The efficacy of colistin monotherapy versus combination therapy with other antimicrobials against carbapenem-resistant Acinetobacter baumannii ST2 isolates. Journal of Chemotherapy, 32(7), 359-367.

Machado, T. D. B., Leal, I. C., Amaral, A. C. F., Santos, K., Silva, M. G. D., \& Kuster, R. M. (2002). Antimicrobial ellagitannin of Punica granatum fruits. Journal of the Brazilian Chemical Society, 13(5), 606-610.

Moody J. Synergism testing: broth microdilution checkerboard and broth macrodilution methods. In: Isenberg HD (Ed.) Clinical Microbiology Procedures Handbook, 2nd ed. Washington, DC: ASM Press, 2007: p.5.12.1-5.12.23.

Mun, S. H., Kang, O. H., Kong, R., Zhou, T., Kim, S. A., Shin, D. W., \& Kwon, D. Y. (2018). Punicalagin suppresses methicillin resistance of Staphylococcus aureus to oxacillin. Journal of pharmacological sciences, 137(4), 317323.

Qureshi, Z. A., Hittle, L. E., O'Hara, J. A., Rivera, J. I., Syed, A., Shields, R. K., ... \& Doi, Y. (2015). Colistin-resistant Acinetobacter baumannii: beyond carbapenem resistance. Clinical infectious diseases, 60(9), 1295-1303.

Rodjun, V., Houngsaitong, J., Montakantikul, P., Paiboonvong, T., Khuntayaporn, P., Yanyongchaikit, P., \& Sriyant, P. (2020). In Vitro Activities of Colistin and Sitafloxacin Combinations against Multidrug-, Carbapenem-, and Colistin-Resistant Acinetobacter baumannii Using the Broth Microdilution Checkerboard and Time-Kill Methods. Antibiotics, 9(8), 516.

Seeram, N. P., Adams, L. S., Henning, S. M., Niu, Y., Zhang, Y., Nair, M. G., \& Heber, D. (2005). In vitro antiproliferative, apoptotic and antioxidant activities of punicalagin, ellagic acid and a total pomegranate tannin extract are enhanced in combination with other polyphenols as found in pomegranate juice. The Journal of nutritional biochemistry, 16(6), 360367.

Trabelsi, A., El Kaibi, M. A., Abbassi, A., Horchani, A., ChekirGhedira, L., \& Ghedira, K. (2020). Phytochemical study and antibacterial and antibiotic modulation activity of Punica granatum (Pomegranate) leaves. Scientifica, 2020.

Xu, Y., Shi, C., Wu, Q., Zheng, Z., Liu, P., Li, G., ... \& Xia, X. (2017). Antimicrobial activity of punicalagin against Staphylococcus aureus and its effect on biofilm formation. Foodborne pathogens and disease, 14(5), 282287. 